\title{
The effect of cognitive behavioral counseling on sexual knowledge, motivation to avoid risky sexual relationships, and sexual depression in female university students
}

\author{
Fatemeh Hosseini, ${ }^{1}$ Katayoun Alidousti Shahraki, ${ }^{2}$ Mansooreh Azizzadeh Forouzi, ${ }^{2}$ \\ Atefeh Ahmadi, ${ }^{1}$ Tania Dehesh $^{3}$
}

\begin{abstract}
Introduction: Misunderstanding of different aspects of sex makes individuals vulnerable to sexual dysfunction, sexually transmitted diseases, mental disorders, and illegal relationships. This study aimed to determine the effect of cognitive behavioral counseling on the sexual self-concept of female students at Kerman University of Medical Sciences.

Methods: This study is an intervention conducted with female students living in dormitories at Kerman and Rafsanjan Universities of Medical Sciences. The sample size was estimated at 63 students from different fields of study; 31 students from Kerman University of Medical Sciences comprised the experimental group and 32 students from Rafsanjan University of Medical Sciences comprised the control group. Cognitive behavioral group counseling sessions were held every 3 days. The instrument used for collecting pre-test and post-test data was Snell's Multidimensional Sexual Self-concept Questionnaire. Data analysis was conducted using measures of central tendency, $t$ tests and chi-square tests.

Results: The two groups were homogenous in terms of demographic factors. Analysis of the results of the intervention revealed significant differences in sexual self-consciousness and motivation to avoid high risk sexual relationships, but there was no significant difference in terms of sexual depression.

Discussion: Cognitive behavioral group counseling can improve sexual self-concept. Therefore, this type of counseling is recommended from younger ages or at enrollment at university, to help correct development of this important part of identity.

Keywords: Concept, sexual, cognitive behavioral counseling.
\end{abstract}

\section{Introduction}

Social changes over recent years in Iran have gradually taken different dimensions. Change is not restricted to values, but the behavior of individuals is also subject to change. A similar shift has taken place in premarital sex also. Recent studies in Iran have shown that about $20-30 \%$ of young people have sexual relations before marriage. ${ }^{1-3}$ One of the most important issues that causes marital conflicts and even divorce in Iranian families is sexual differences and discord between couples, which also destroys the warmth of the family. ${ }^{4}$

Sexual self-concept is defined as an individual's feelings, and beliefs about sex. Self-assessment can be an important predictor of future sexual behaviors and

\footnotetext{
${ }^{1}$ Midwifery Department, Razi Faculty of Nursing and Midwifery, Kerman University of Medical Sciences, Kerman, Iran. ${ }^{2}$ Nursing Research Center, Midwifery Department, Razi Faculty of Nursing and Midwifery, Kerman University of Medical Sciences, Kerman, Iran. ${ }^{3}$ Department of Epidemiology and Biostatistics, School of Public Health, Kerman University of Medical Sciences, Kerman, Iran.

Submitted Sep 04 2018, accepted for publication Aug 022019.

Suggested citation: Hosseini F, Alidousti Shahraki K, Azizzadeh Forouzi M, Ahmadi A, Dehesh T. The effect of cognitive behavioral counseling on sexual knowledge, motivation to avoid risky sexual relationships, and sexual depression in female university students. Trends Psychiatry Psychother. 2020;42(2):122-128. http://dx.doi.org/10.1590/2237-6089-2019-0052
} 
so encouraging it can help people enhance their sexual and psychological well-being. ${ }^{5,6}$

The first stage of sexual self-concept begins in early adolescence and it continues to develop over the course of a person's lifetime. Snell et al., ${ }^{5}$ have defined 20 subcategories for sexual self-concept, including sexual anxiety, sexual self-efficacy, sexual awareness, motivation to avoid risky relationships, accidental control of sexual desires, sexual desire, sexual courage, sexual optimism, self-blaming in sexual problems, sexual monitoring, sexual excitability, sexual issue management, reliability and sexual value, sexual satisfaction, sexual control by influential people, individual sexual patterns, fear of sexual relations, prevention of sexual problems, sexual depression, and internal control of sexual issues. ${ }^{5}$

Sexual self-concept helps a person achieve knowledge, identity, and self-assessment in sexual life. It organizes and provides the structure and motivation to build relationships, behavior, self-esteem, and sexual anxiety in the present and in the future. Snell et al. ${ }^{5}$ believe that sexual self-concept is a predictor of sexual health, sexual risk awarness, and sexual self-efficacy. In other words, low self-esteem and negative sexual self-concept are predictors of risky sexual behavior. 5,6 A proportion of sexual dysfunctions are associated with poor sexual self-concept. 7,8

Studies have shown that factors such as age, sex, siblings, school, mass media, sexual education, sexually transmitted diseases, and social and cognitive changes impact sexual self-concept.9-13 The pattern of sexual relations has many variations in the world and in Iran the values and beliefs of young people are undergoing extensive changes. Premarital sex and home-sharing among young people are on the rise. ${ }^{14}$ Haghdoost et al. ${ }^{15}$ have claimed that the pattern of HIV transmission has changed from IV drug users to the general population, which is due to unsafe sexual contact. ${ }^{15}$ In 2014, a study was conducted with 363 newlywed women in Sari, Iran, finding that $21.2 \%$ of the women had sexual dysfunction. ${ }^{16}$ The sexual presentation of a person in the community is related to his/her sexual self-concept. ${ }^{17}$ Lack of sex education and counseling for young people in schools, universities, and families has led to the creation of sexual myths and poor sexual selfconcept among individuals. ${ }^{18}$

Since the World Health Organization has declared that sexual health is a correlation between physical, emotional, rational, and social aspects in beings with sexual instinct, and states that "sexual health increases the richness of personality, relationships and love", people of all ages and backgrounds are prone to sexual dangers, and need to be aware of and have access to services in the field of sexual health. ${ }^{19}$
Considering the importance of sexual self-concept, which can place people at different risks, this study aimed to investigate the effect of cognitive behavioral counseling on sexual self-concept in female university students.

\section{Methods}

This clinical trial was designed to investigate the effect of counseling on sexual self-concept in female university students.

\section{Participants and procedures}

The study population consisted of all female students at Kerman University of Medical Sciences. The sample size was calculated as 27 in each group, based on similar previous studies ${ }^{20}$ and taking into account $80 \%$ $(\beta)$ test power and $5 \%$ (a) error probability. The 27 students in the intervention group were selected from Kerman University and 27 students were selected from Rafsanjan University for a control group. To account for expected missing data, 32 participants were selected for the control group and 31 students were selected for the intervention group.

Inclusion criteria were being single, being able to speak and understand Persian, being from Iran (due to differences in culture, customs, and lifestyle), not having a history of known psychiatric illnesses, and not taking psychiatric medications (self-declaration).

Using other relevant counseling services and not attending one of the counseling sessions were defined as exclusion criteria.

After selecting the samples and obtaining informed consent from all participants, the pretest was administered. The intervention group was then divided into three subgroups (maximum 10 participants in each group). These subgroups underwent 6 consecutive cognitive-behavioral counseling sessions once every 3 nights (educational materials are presented in Table 1).

Table 1 - Sessions and Meeting Titles

\begin{tabular}{ll}
\hline Sessions & Meeting titles \\
\hline First session & Understanding needs of sex \\
Second session & How does excitement form? \\
Third session & Identifying negative schemas \\
Fourth session & $\begin{array}{l}\text { Identifying damaging thoughts } \\
\text { Fifth session }\end{array}$ \\
$\begin{array}{l}\text { Identifying intellectual patterns or } \\
\text { intellectual errors } \\
\text { Sixth session }\end{array}$ & $\begin{array}{l}\text { Elaborating on thinking patterns for } \\
\text { dealing with problems }\end{array}$ \\
\hline
\end{tabular}

Trends Psychiatry Psychother. 2020;42(2) - 123 
The duration of each session was one hour and thirty minutes. At the end of the last counseling session, participants who had attended all sessions were asked to complete a post-test. At the same time, the questionnaire was also completed by control group members. In order to uphold the principles of ethical conduct, a summary of the counseling sessions was presented in 2 sessions to control group members after they had completed the post-test.

\section{Instruments}

Demographic and health characteristics were assessed using a questionnaire designed by the researchers. Sexual self-concept was measured using Snell's multi-dimensional questionnaire.

The demographic information analyzed included age, sex, marital status, religion, number of siblings, household income, and parents' educational levels. Additional questions covered present psychological problems and use of sedatives, anti-depressants, and anxiolytics. Snell's multifaceted self-concept questionnaire is an objective self-report tool that is designed to measure 20 psychological dimensions in the sexual sphere. ${ }^{6}$ The questionnaire comprises 100 items with responses scored on a 5-point Likert scale from 0 ("this is by no means true about me") to 4 ("this is absolutely true about me"). Each dimension consists of 5 items, and the total score is evaluated separately for each dimension.

The validity and reliability of this questionnaire were estimated by Ziaei et al., ${ }^{21}$ using a content validity index (at 0.70 and 0.88 , respectively). ${ }^{21}$ Bearing in mind the socio-cultural aspects of conducting such a study in an Iranian community, three areas of sexual self-concept were selected for investigation (sexual awareness, motivation to avoid high-risk relationships, and sexual depression). The study was conducted after approval was granted by the Deputy of Research at Kerman University of Medical Sciences (2016. 272kmu. Rec.) and a clinical trial code was obtained (IRCT2017071624866N3).

\section{Data analysis}

Data analysis was performed using the Statistical Package for the Social Sciences (SPSS) version 22 (SPSS, Inc., Chicago, IL, USA), running independent $t$ tests, paired $t$ tests, and chi-square tests. To ensure that demographic variables did not affect the results, intervention and control groups were matched in this regard before initiating the study. Nevertheless, the relationship between the two groups and each of the demographic variables were investigated using the chi- square test. Shapiro-Wilk and Kolmogorov tests were used to determine the normality of the data and the level of significance was set at $p<0.05$.

\section{Results}

\section{Demographic characteristics}

Although most of the participants in the control group were aged between 17 and 21 and those in the intervention group were aged between 21 and 25 years, this difference was not statistically significant $(p=0.09)$. In terms of father's educational level, it was found that most of intervention group's fathers had a diploma, but most of control group's fathers were undergraduates. Nevertheless, the two groups did not differ significantly in this regard $(p=0.38)$. In the intervention group, $32.3 \%$ of mothers had undergraduate education and $31.3 \%$ of control group mothers had postgraduate education. In the intervention group, 16 participants (51.6\%) had one sister, and in the control group, 12 of the participants (37.5\%) had no sisters. About $38.5 \%$ and $46.9 \%$ of the intervention group and the control group respectively had one brother (Table 2 ).

\section{Sexual self-concept}

The differences between mean scores before and after counseling were not statistically significant for any of the three sexual self-concept dimensions in the control group $(p<0.05)$.

In contrast, the analysis revealed significant statistical differences between the pre-test and posttest scores in the intervention group for all aspects of sexual self-concept $(p \leq 0.05)$.

Comparison of mean scores of sexual self-concept dimensions before counseling showed a significant difference between the two groups in terms of the avoidance of high-risk sexual relationships dimension only, and so the two groups did not match in this respect at study outset $(p=0.001)$ (Table 3 ).

The difference between mean scores for highrisk sexual relationship avoidance before and after counseling was greater in the intervention group than in the control group and the mean score significantly increased in the intervention group $(p<0 / 05)$.

There was no significant difference between intervention and control groups regarding mean pre-test and post-test scores for sexual depression ( $p>0.05$ ).

Intervention increased the mean score for the sexual awareness dimension $(p<0.05)$ (Table 4). 
Effect of counseling on sexual self-concept - Hosseini et al.

Table 2 - Frequency distributions and percentages for demographic characteristics (intervention and control group)

\begin{tabular}{|c|c|c|c|}
\hline Group & Intervention & Control & Result \\
\hline \multicolumn{4}{|l|}{ Age } \\
\hline 17-21 years old & $13(41.9 \%)$ & $20(62.5 \%)$ & \multirow{3}{*}{$\begin{array}{c}x^{2}=4.80 \\
d f=2 \\
p=0.09\end{array}$} \\
\hline 21-25 years old & $15(48.4 \%)$ & $12(37.5 \%)$ & \\
\hline 25-29 years old & $3(9.7 \%)$ & $0(0)$ & \\
\hline \multicolumn{4}{|l|}{ Father's education } \\
\hline None & $1(3.2 \%)$ & $2(6.3 \%)$ & \multirow{5}{*}{$\begin{array}{c}x^{2}=4.185 \\
d f=4 \\
p=0.38\end{array}$} \\
\hline High school & $10(32.3 \%)$ & $6(18.8 \%)$ & \\
\hline Diploma & $11(35.5 \%)$ & $9(28.1 \%)$ & \\
\hline Bachelor & $7(22.6 \%)$ & $14(43.8 \%)$ & \\
\hline Masters and higher & $2(6.5 \%)$ & $1(3.1 \%)$ & \\
\hline \multicolumn{4}{|l|}{ Mother's education } \\
\hline None & $2(6.5 \%)$ & $3(9.4 \%)$ & \multirow{5}{*}{$\begin{array}{c}x^{2}=1.164 \\
d f=4 \\
p=0.88\end{array}$} \\
\hline High school & $10(32.3 \%)$ & $10(31.3 \%)$ & \\
\hline Diploma & $9(29 \%)$ & $7(21.9 \%)$ & \\
\hline Bachelor & $7(22.6 \%)$ & $10(31.3 \%)$ & \\
\hline Masters and higher & $3(9.7 \%)$ & $2(6.3 \%)$ & \\
\hline \multicolumn{4}{|l|}{ Sisters } \\
\hline 0 & $6(19.4 \%)$ & $12(37.5 \%)$ & \multirow{5}{*}{$\begin{array}{c}t=-0.05 \\
d f=61 \\
p=0.96\end{array}$} \\
\hline 1 & $16(51.6 \%)$ & $5(15.6 \%)$ & \\
\hline 2 & $5(16.1 \%)$ & $7(21.9 \%)$ & \\
\hline 3 & $2(6.5 \%)$ & $6(18.8 \%)$ & \\
\hline $4-7$ & $2(6.4 \%)$ & $2(6.2 \%)$ & \\
\hline \multicolumn{4}{|l|}{ Brothers } \\
\hline 0 & $11(35.5 \%)$ & $8(25 \%)$ & \multirow{4}{*}{$\begin{array}{c}t=0.87 \\
d f=61 \\
p=0.39\end{array}$} \\
\hline 1 & $12(38.5 \%)$ & $15(46.9 \%)$ & \\
\hline 2 & $0(0)$ & $8(25 \%)$ & \\
\hline 3 & $3(9.7 \%)$ & $1(3.1 \%)$ & \\
\hline
\end{tabular}

Table 3 - Comparison of mean scores of sexual self-concept dimensions before and after counseling between two groups

\begin{tabular}{|c|c|c|c|}
\hline Dimension/time & Intervention & Control & Result \\
\hline \multicolumn{4}{|l|}{ Sexual awareness } \\
\hline Before intervention & 10.48 & 12.78 & $\begin{array}{c}t=-2.82 \\
d f=61 \\
p=0.09\end{array}$ \\
\hline \multirow[t]{2}{*}{ After intervention } & 13.48 & 12.06 & \\
\hline & $\begin{array}{c}t=6.22 \\
d f=31 \\
p=0.00\end{array}$ & $\begin{array}{c}t=-1.53 \\
d f=31 \\
p=0.14\end{array}$ & \\
\hline \multicolumn{4}{|c|}{ Avoiding high-risk sexual relationships } \\
\hline Before intervention & 16.48 & 18.78 & $\begin{array}{c}t=-2.843 \\
d f=61 \\
p=0.001\end{array}$ \\
\hline \multirow[t]{2}{*}{ After intervention } & 18.32 & 18.38 & \\
\hline & $\begin{array}{c}t=32.76 \\
d f=31 \\
p=0.00\end{array}$ & $\begin{array}{c}t=-1.26 \\
d f=31 \\
p=0.22\end{array}$ & \\
\hline \multicolumn{4}{|l|}{ Sexual depression } \\
\hline Before intervention & 14.48 & 14.84 & $\begin{array}{c}t=-0.56 \\
d f=60 \\
p=0.40\end{array}$ \\
\hline \multirow[t]{2}{*}{ After intervention } & 16.11 & 15.38 & \\
\hline & $\begin{array}{c}t=3.066 \\
d f=31 \\
p=0.01\end{array}$ & $\begin{array}{c}t=0.90 \\
d f=31 \\
p=0.37\end{array}$ & \\
\hline
\end{tabular}


Table 4 - Comparison of the relative changes in the sexual self-concept scores in the intervention and control groups

\begin{tabular}{|c|c|c|c|}
\hline Group & Intervention & Control & T-test \\
\hline Sexual awareness & 0.3521 & -0.0404 & $\begin{array}{c}\mathrm{t}: 5.223 \\
\mathrm{df}=48.122 \\
\mathrm{p}=0.027\end{array}$ \\
\hline Avoiding high-risk sexual relationships & 0.1433 & -0.0179 & $\begin{array}{c}t: 30.049 \\
d f=38.254 \\
p=0.005\end{array}$ \\
\hline Sexual depression & 0.1590 & 0.641 & $\begin{array}{c}\mathrm{T}: 1.331 \\
\mathrm{df}=61 \\
\mathrm{p}=0.803\end{array}$ \\
\hline
\end{tabular}

\section{Discussion}

The findings demonstrated that cognitive behavioral counseling led to an increase in female students' sexual knowledge. Snell et al. defined sexual knowledge as the tendency to think and react to sexual nature. ${ }^{5}$ Sexual knowledge is understanding of one's sexual characteristics such as sexual shame, feeling nervous or uncomfortable during intercourse, and sexual self-esteem. One's awareness of the above issues and their elimination can be a factor in achieving sexual satisfaction. Understanding sexual aspects and recognizing sexual thoughts, attitudes, actions, and feelings leads to greater sexual satisfaction. On the other hand, a positive framework of sexual selfawareness can lead to a positive sexual identity. ${ }^{22}$

Given that in some countries talking about sex issues is taboo and that girls and boys nowadays reach puberty at a younger age all over the world, marry later, and engage in sexual acts before they get married, familiarity with sexual issues before marriage can reduce abnormal behaviors, as long as this information is free from false beliefs. ${ }^{23-26}$

Some studies have shown that cognitive behavioral training had effects on women's sexual knowledge, attitude, and self-confidence. ${ }^{19,27,28}$ In the present study, female university students' sexual habits, thoughts, beliefs, myths, central beliefs, and selfawareness were studied, and it was revealed how these matters triggered individuals' emotions, behaviors, and reactions in different situations.

We also found that cognitive behavioral counseling affected the motivation to avoid high-risk relationships dimension, which is consistent with previous findings. $20,29,30$

The experience of having sex during adolescence and youth, without adequate awareness, can lead to the maintenance of high-risk relationships and can have consequences such as sexually transmitted diseases, unwanted pregnancy, or many other problems of this nature. Preventive measures regarding high-risk relationships are among the most important interventions that can be employed to save a person from premarital sexual relationships. The fact that young people often have no experience in this field and only think about one aspect of it, is enough to demonstrate the need for such interventions. ${ }^{31}$ In 2010, the United States' Centers for Disease Control and Prevention reported that $46 \%$ of high school students had sexual experience, and 34\% of them had experienced sex during the previous three months. It was also found that among sexually active individuals, 39\% had not used condoms during their last sexual contact and $14 \%$ of them had had sex with 4 or more people during their lifetimes. ${ }^{32}$ Research about sexual behavior conducted in the United States is cited because there is a lack of this kind of study in Iran.

Rahmani et al., ${ }^{33}$ concluded that inability to terminate a relationship, to make the right decision, and to reject sex are factors that affect young girls' involvement in sexual relationships. They emphasized the need for prevention through counseling and training in this regard. They also mentioned that sexually active young people who did not use any method or means of contraception had a $90 \%$ chance of pregnancy during a one-year sexual relationship. More than 50 percent of new HIV infections occur in young people in the 2530 -year age range. In other words, young people are more likely to be exposed to this virus than any other age group. ${ }^{33}$

Merghati Khoei ${ }^{34}$ states that in many girls, sexual intercourse is based on the awareness of virginity, and sexual intercourse in girls is the product of interactions with the opposite sex and creation of interest and dependency. It seems that dependence is caused by temporary emotions. In order to satisfy emotional needs and maintain the relationship with the opposite sex, girls resort to unconditional acceptance of sexual propositions, further exposing themselves to early and perilous sexual activities. The reason for agreeing to sexual intercourse by girls is to keep in touch with the 
opposite sex and achieve marriage. Girls are more concerned about social dignity than boys; and do not have sufficient health information about complications of sexual relations, such as sexually transmitted diseases. ${ }^{33,34}$

Maladaptive thoughts act automatically and unknowingly in certain situations and can cause negative emotions. These thoughts also interfere with emotional and behavioral responses to sexual situations. ${ }^{35}$ Cognitive behavioral counseling focuses on rebuilding irrational attitudes, beliefs, and behaviors in this regard.

When a person experiences feelings such as shame, embarrassment, and humiliation, he/she may confront sexual depression. ${ }^{6}$

In the present study, it was found that behavioral counseling did not have any significant effect on the sexual depression aspect of sexual self-concept, which is in line with findings of a study by Jaafarpour et al., ${ }^{35}$ but in contrast to those reported by Rahmani et al. ${ }^{24}$ and Ghorbanshiroudi. ${ }^{36}$ This discrepancy in findings may be due to the fact that in the study by Ghorbanshiroudi, sexual education was administered to married people, since people speak more comfortably about sexual problems after their marriage. Depression is a key factor in reducing self-esteem and sexual dignity.

Counseling was not able to exert a significant effect on sexual depression among our participants. This finding can be attributed to the fact that the issue of depression is highly specialized and sexual depression cannot be treated in a few group counseling sessions. It seems that overcoming sexual depression requires individual counseling or even medication in more severe cases. Depression reduces sexual desire, sexual arousal, frequency of sexual intercourse and achievement of orgasm, self-confidence, self-esteem, sexual performance, and sexual dysfunctions. 5,37,38 Many studies of sexual activity among patients suffering from depression have shown that depression and antidepression drugs have numerous side-effects on the sexual activity of these patients and can endanger their sexual health. One reason for lack of counseling effect on sexual depression may be the brevity of the intervention. It seems that overcoming sexual depression requires a different type of counseling method or a longer duration intervention, which may be a limitation of this study.

\section{Acknowledgement}

This research was supported by Kerman University of Medical Sciences. We are thankful to all participants who kindly cooperated with us to perform this study.

\section{Disclosure}

No conflicts of interest declared concerning publication of this article.

\section{References}

1. Farahani FK, Cleland J, Mehryar AH. Associations between family factors and premarital heterosexual relationships among female college students in Tehran. Int Perspect Sex Reprod Health. 2011;37:30-9.

2. Malek A, Shafiee-Kandjani AR, Safaiyan A, Abbasi-Shokoohi H. Sexual knowledge among high school students in Northwestern Iran. ISRN Pediatr. 2012;2012:645103.

3. Mohammad K, Khalaj F, Farahani A, Mohamad MR, Alikhani S, Zare $M$, et al. Sexual risk-taking behaviors among boys aged 15-18 years in Tehran. J Adolesc Health. 2007;41:407-14.

4. Deutsch AR. A test of a conceptual model of sexual self-concept and its relation to other dimensions of sexuality. Lincoln: University of Nebraska; 2012.

5. Snell Jr WE. New directions in the psychology of human sexuality: research and theory. Cape Girardearu: Snell Publications; 2001. p. $170-93$.

6. Steinke EE, Wright DW, Chung ML, Moser DK. Sexual self-concept, anxiety, and self-efficacy predict sexual activity in heart failure and healthy elders. Heart Lung. 2008;37:323-33.

7. Bleakley A, Hennessy M, Fishbein M, Jordan A. It works both ways: the relationship between exposure to sexual content in the media and adolescent sexual behavior. Media Psychol. 2008;11:44361.

8. Bobkowski PS, Shafer A, Ortiz RR. Sexual intensity of adolescents' online self-presentations: joint contribution of identity, media consumption, and extraversion. Comput Human Behav. 2016;58:64-74.

9. Armstrong JL. Sexual self-concept and college adjustment [dissertation]. Ann Arbor: Regent University; 2011.

10. Aubrey JS. Does television exposure influence college-aged women's sexual self-concept? Media Psychol. 2007;10:157-81.

11. Herring SC, Kapidzic S. Teens, gender, and self-presentation in social media. In: International Encyclopedia of Social and Behavioral Sciences. 2nd ed. Oxford: Elsevier; 2015. p. 1-16.

12. Azad AT, SHarifi SMH, Isari M, Talebi S. Cohabitation: the new family pattern in Tehran. Cult Sociology. 2012;2:1-34.

13. Mohammad ACS, Mirghafourvand M, KHaki RZ, Malakouti J, Asghari JAM, Ghanbari S. Sexual dysfunction and help seeking behavior in newly married women in Sari, Iran: a cross-sectional study. Caring Sci. 2015;4:143-53.

14. Rahimi M, Mohseni M, Bostan H, Parsipour S, Darabi E, Mohammadzadeh $\mathrm{T}$. The prevalence of intestinal parasites in the patients referred to the laboratories of Baqiyatallah Hospital during 2010-2014. J Ardabil Univ Med Sci. 2016;15:414-22.

15. Haghdoost AA, Mostafavi E, Mirzazadeh A, Navadeh S, Feizzadeh A, Fahimfar N, et al. Modelling of HIV/AIDS in Iran. J AIDS HIV Res. 2011;3:231-9.

16. Rostosky SS, Dekhtyar O, Cupp PK, Anderman EM. Sexual selfconcept and sexual self-efficacy in adolescents: a possible clue to promoting sexual health? J Sex Res. 2008;45:277-86.

17. Glasier A, Gülmezoglu AM, Schmid GP, Moreno CG, Van Look PF. Sexual and reproductive health: a matter of life and death. Lancet. 2006;368:1595-607.

18. Farmer RF, Chapman AL. Behavioral interventions in cognitive behavior therapy: practical guidance for putting theory into action. Washington: American Psychological Association; 2016.

19. Modjarrad, K, Giersing B, Kaslow DC, Smith PG, Moorthy VS; the WHO RSV Vaccine Consultation Expert Group. WHO Consultation on Respiratory Syncytial Virus Vaccine Development Report from a World Health Organization Meeting held on 23-24 March 2015. Vaccine. 2016;4:190-7.

20. Ramezani MA, Ahmadi K, Ghaemmaghami A, Zamani S, Saadat SH, Rahiminejad SP. Evaluation of quality of life therapy effectiveness in contrast to psycho-sexual education on sexual self-concept of Iranian women. Iran Red Crescent Med J. 2018;20:22424.

21. Ziaei T, Merghati Khoei E, Salehi M, Farajzadegan Z. Psychometric properties of the Persian version of modified Multidimensional 
Sexual Self-concept Questionnaire. Iran J Nurs Midwifery Res. 2013;18:439-45.

22. Janghorban R, Latifnejad Roudsari R, Taghipour A, Abbasi M. A review of the concept and structure of sexual and reproductive rights in international human rights documents. Iran J Obstet Gynecol Infertil. 2014;17:16-26.

23. Atadokht A, Ranjbar M J, Gholami F, Nazari T. Students drive towards risk-taking behaviors and its relationship with demographic variables and psychological well-being. J Health Care. 2013;15:50-9

24. Rahmani A, Merghati-Khoei E, Fallahi A. Perceived advantages and disadvantages of sex education in young women: a qualitative study. Int J High Risk Behav Addict. 2018;7:57221.

25. Latif Nejad R, Jvad Nouri M, Hasanpour M, Hazaveyi SMM, Taghipour A. The necessity of sexual-health education for Iranian female adolescents: a qualitative study. Iran J Obstet Gynecol Infertil. 2012;15:7-17.

26. Amini M, Moradi A, Momeni KH, Pvrrshydy M. Sex education effectiveness of cognitive-behavioral sexual self-concept. In: The First International Congress of Psychology. Tehran: Iran's Development Convention Center; 2015.

27. Rahimi E, Shafiabadi A, Yunesi F. The effect of sexual cognitivebehavioral therapy on females' sexual knowledge, sexual attitude, and sexual self-confidence. A case study in Shiraz, Iran. Armaghane Danesh. 2009;14:103-11.

28. Rantanen AP, Soini HS. Changes in counsellor trainee responses to client's message after peer group consultation (PGC) training. $\mathrm{Br}]$ Guid Counsel. 2018;46:531-42.

29. Pakgohar M, Mirmohammadali M, Mahmoudi M, Farnam F. Effect of pre-marriage counseling on the sexual health. Hayat. 2006;11:39-45.

30. Amir zade N, Amir zade J, Khalil zade H. Developing adolescent girls health status with education of sexual high-risk behavior prevention (HIV) in Uremia University of Medical Science. Nurs Midwifery J. 2008;6:113-6.
31. Zarie F, Khakbaz $H$, Karami H. Determining the effectiveness of self-awareness skill training on reducing high-risk behaviors associated with the opposite sex addict. Res Addict. 2010;4:6370.

32. Centers for Disease Control and Prevention. Sexual experience and contraceptive use among female teens-United States, 1995, 2002, and 2006-2010. MMWR Morb Mortal Wkly Rep. 2012;61:297.

33. Rahmani A, Merghati Khoei E, Moghaddam-Banaem L, Montazeri A, Hajizadeh E. How self-efficacy impacts on young women' risky sexual behavior? A qualitative study. J Qual Res Health Sci. 2015;4:73-86.

34. Merghati-Khoei E, Shams Alizadeh N, Bayat A, Zarei F, Rimaz S. Priorities of health risk behaviors among high school students in the public schools in 5th restrict of Tehran: a qualitative study. J School Public Health Inst Public Health Res. 2014:12:69-80.

35. Jaafarpour M, Maroufi M, Molaeinezhad M. Relationship between sexual self-concept and sexual performance in married women referring to Mobarakeh health centers, Iran. J Res Dev Nurs Midwifery. 2016;12:40-7.

36. Ghorbanshiroudi S, Azari N, Khalatbari J, Keikhayfarzaneh MM. Studying the effectiveness of cognitive-behavioral therapy in developing sexual self-concept. J Basic Applied Sci Res. 2012;2:3381-8.

37. Delgado-Parra V, Rojas-Flores A, Rubio-Aurioles E. 396 Selfreported depression: its impact on sexual satisfaction and sexual function, an internet-based survey. J Sex Med. 2017;141:118.

38. Hosseininasab A, Alidoosti K, Forouhari S. Health-related counseling needs in adolescent girls. Health Scope.2016;5:24601.

\section{Correspondence:}

Katayoun Alidousti Shahraki

Tel.: +0989132421749, Fax: +0983431325218

E-mail: alidoosti@kmu.ac.ir 